\title{
Adaptive Hybrid Fuzzy PI-LQR Optimal Control using Artificial Immune System via Clonal Selection for Two-Area Load Frequency Control
}

\author{
Muhammad Abdillah \\ Department of Electrical Engineering, Universitas Pertamina \\ Jalan Teuku Nyak Arief, Simprug, Kebayoran Lama, Kota Jakarta Selatan, Indonesia 12220 \\ m.abdillah@universitaspertamina.ac.id
}

\begin{abstract}
Load frequency control (LFC) problem has been a foremost issue in electrical power system operation and is becoming more important recently with growing size, changing structure, and complexity in interconnected power systems. In general, LFC system utilizes simple proportional integral (PI) controller. However, due to the PI control parameters are commonly adjusted based on classical or trial-error method (TEM), it is incapable of obtaining good dynamic performance for a wide range of operating conditions and various load change scenarios in a multi-area power system. This paper introduces a novel control scheme for load frequency control (LFC) using hybrid fuzzy proportional integral (fuzzy PI) and linear quadratic regulator (LQR) optimal control, where fuzzy logic control (FLC) is used to adjust the gains $\mathbf{K}_{P}$ and $\mathbf{K}_{I}$ of PI controller which called fuzzy PI in this paper, while the LQR optimal control method is employed to obtain the feedback gain $\mathbf{K}_{O P}$ through Algebraic Riccati Equation (ARE). The merit of both control strategies is to tune their control feedback gains, which are $\mathbf{K}_{P}, \mathbf{K}_{I}$ and $\mathbf{K}_{O P}$, regarding various system operating conditions. Artificial immune system (AIS) via clonal selection is utilized to optimize the membership function (MF) of fuzzy PI and weighting matrices $\mathbf{Q}$ and $\mathbf{R}$ of LQR optimal control in order to obtain their optimal feedback gains. To examine the efficacy of the proposed method, LFC of two-area power system model is utilized as a test system. The amalgamation of fuzzy PI-LQR is applied to improve the dynamic performance of two-area LFC. Other control schemes such as PI controller, hybrid PI controllerLQR, and hybrid fuzzy PI-LQR are also investigated to the studied a test system. The obtained simulation results show that the proposed method could compress the settling time and decrease the overshoot of LFC which is better than other approaches that are also employed to the tested system in this study.
\end{abstract}

Keywords: Lfc; fuzzy pi; lqr; ais; dynamic performance

\section{Introduction}

Stability plays an important role in power system operation regarding maintaining and guaranteeing the electrical power that is transferred from generation units to the customer demand side through a transmission line in secure and reliable [1]. The stability of the power system can also be affected by small or large disturbances. Disturbance, that influences the system stability degree on power system, may be classified into two types, that are, transient such as short circuit, and dynamic such as small load change continuously.

Load change, which is a kind of dynamic disturbance on power system network, affects the frequency change during system operation. Therefore, a control system called load frequency control (LFC) is required as the main part of power system in order to maintain the frequency on its nominal value during exchange power in the power system grid on which the generator dispatch must guarantee the stability of power system. Many studies in the research area of the LFC problem on power system networks have been reported [2-5]. To attain better dynamic performance, several control scenarios have been applied in the design of LFC. From various types of control schemes, the PI controller is most widely applied to the LFC power system model $[2,4,6,7]$ due to its control scheme is simple for implementation but commonly provides

Received: July $5^{\text {th }}, 2018$. Accepted: September $13^{\text {rd }}, 2020$

DOI: $10.15676 /$ ijeei.2020.12.3.14 
large-frequency oscillations. Due to the PI controller is commonly designed with fixed gains at nominal operating environments, it fails to give the best control achievement over a wide range of operating conditions and shows poor dynamic performances. To tackle this problem, hybrid control design strategies with other types of controllers are required to increase the dynamic performance of LFC under disturbance.

The linear quadratic regulator (LQR) optimal control is one of many control design approaches utilized to improve the stability performance of system operation. Based on LQR optimal control theory, a set of optimal feedback gains may be obtained by minimizing a quadratic index and ensure system operation in stable condition $[8,9]$. The employments of LQR optimal control for excitation controller design, energy-efficient of electric vehicles, and decentralized control design of multi-area LFC power system models have been reported in [1012] and performed well results. Hybrid PI controller and LQR optimal control may improve the oscillation damping of LFC power system. Nevertheless, the determination of their control design parameters by using conventional methods involves many trial-error actions and takes a long time to find their optimal feedback gains.

To date, fuzzy logic control (FLC) has been applied worldwide as an alternative control design for various system models [13-17] due to FLC can be easily employed in a practical system and not sensitive to the variations of system structures, parameters, and operating points. However, so far both membership function and control rule of FLC are commonly chosen by trial-error approach or experience of designers. FLC is utilized to set the parameters of PI controller automatically which is called fuzzy PI to adapt to the changes in operating conditions.

Hybrid fuzzy PI and LQR optimal control to improve the dynamic performance of two-area LFC is introduced in this study. Due to the determination of fuzzy PI membership functions and elements of LQR optimal control by trial-error method have difficulties in gaining the control purposes in the presence of changing the operating points such as load changes under which the model is derived, and lack of system components, meta-heuristic is one of optimization approaches can be employed to obtain the optimal their control scheme parameters. One of metaheuristic methods utilized in solving a complex problem in optimization research field is an artificial immune system (AIS) via clonal selection where successfully applied for various study cases [18-23] and provides satisfactory results. In [18], the optimal solution obtained by AIS via clonal selection is better than optimal solution produced by a genetic algorithm (GA). Furthermore, the AIS via clonal selection is more efficient than other classical meta-heuristic algorithms such as simulated annealing (SA), tabu search (TB), and genetic algorithm (GA) [19]. Meta-heuristic algorithms such as teaching-learning-based optimization (TLBO) [24] and harmony search algorithm (HSA) [25] have successfully applied for solving LFC problem. AIS via clonal selection had received much attention regarding its potential as a global optimization approach and it has been employed on power system research field as reported in [26-28].

This paper proposes AIS via clonal selection to tune the membership function of fuzzy PI and weighting matrices $\mathbf{Q}$ and $\mathbf{R}$ of LQR optimal control as to obtain feedback controller gains $\mathbf{K}_{P}, \mathbf{K}_{I}$, and $\mathbf{K}_{O P}$ where applied for two-area LFC power system model. The fuzzy PI and weighting matrices $\mathbf{Q}$ and $\mathbf{R}$ of LQR optimal control are important parameters that obtaining optimal feedback gains $\mathbf{K}_{P}, \mathbf{K}_{I}$ and $\mathbf{K}_{O P}$ in order to improve the dynamic performance of twoarea LFC model by observing the change of frequency caused by load change.

This paper is organized as follows. The description of load frequency control and its control scheme model is provided in section 2. Section 3 introduces the proposed method. The proposed method is described in section 4. Simulation results and discussions are illustrated in section 5. Concluding remarks are made in section 6.

\section{Two-Area LFC Model Equipped with Proposed Controller}

\section{A. Two-Area LFC Model}

The structure of two-area LFC in the linear model utilized in this paper is described in Figure 1. 


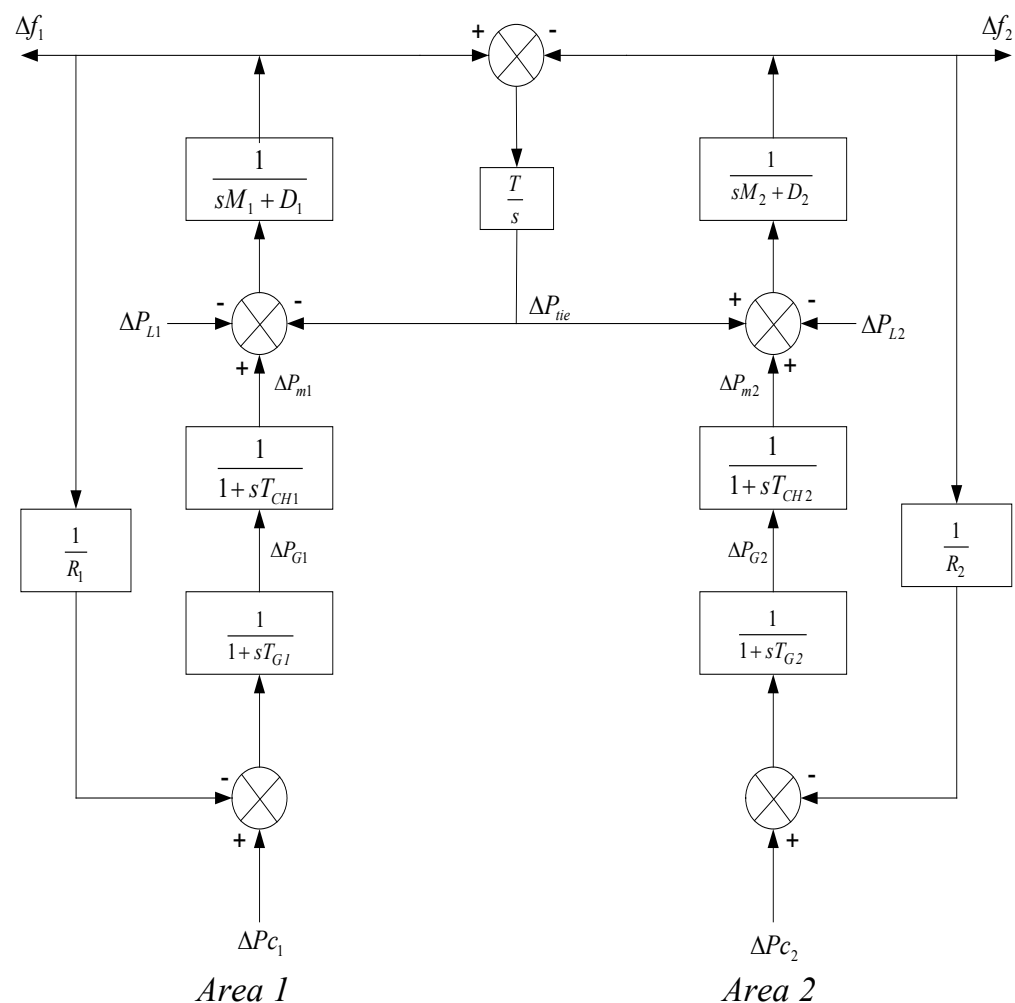

Figure 1. Linear model of two-area load frequency control

where $M_{1,2}, T_{C H 1,2,} T_{G 1,2} R_{1,2}, T$ are constant of inertia in area 1 or 2 , turbine time constant in area 1 or 2 , governor time constant in area 1 or 2 , speed droop in area 1 or 2 , and tie-line synchronization constant, respectively. While $\Delta f_{1,2}, \Delta P_{m 1,2}, \Delta P_{G l, 2}, \Delta P_{\text {tie }}$ are frequency deviation in area 1 or 2 , mechanic power deviation in area 1 or 2 , deviation of governor level in area 1 or 2 , and deviation of tie-line power.

The linear model of two-area LFC is transformed into state-space equation forms in (1)-(2).

$$
\begin{aligned}
& \dot{x}(t)=\mathbf{A} x(t)+\mathbf{B} u(t)+\mathbf{L} d(t) \\
& y(t)=\mathbf{C} x(t)
\end{aligned}
$$

where $\mathbf{A}, \mathbf{B}, \mathbf{C}, \mathbf{L}, x(t), u(t), d(t), y(t)$ are system matrix, input matrix, output matrix, disturbance matrix, state variable, input variable, disturbance variable, and output variable. State variable $x(t)$ in (1) can be re-written as $x(t)=\left[\Delta f_{1} \Delta P_{m 1} \Delta P_{G 1} \Delta P_{\text {tie }} \Delta f_{2} \Delta P_{m 2} \Delta P_{G 2}\right]^{\mathrm{T}}$. While input variable $u(t)$ consist of two inputs $u(t)=\left[\begin{array}{ll}u_{1} & u_{2}\end{array}\right]^{\mathrm{T}}=\left[\begin{array}{ll}\Delta P_{c l} \Delta P_{c 2}\end{array}\right]^{\mathrm{T}} . \Delta P_{c 1,2}$ is control input deviation in area 1 or 2 . Variable for disturbance as representative of load change is defined as $d(t)=\left[\begin{array}{ll}d_{1} & d_{2}\end{array}\right]^{\mathrm{T}}=\left[\begin{array}{lll}\Delta P_{L 1} & \Delta P_{L 2}\end{array}\right]^{\mathrm{T}}$. Where $\Delta P_{L 1,2}$ is load change in area 1 and 2. Area control error $(A C E)$ on LFC is mainly utilized as input signal for supplementary controller. Thus, the system output of LFC can be defined as in (3).

$$
y(t)=\left[\begin{array}{l}
y_{1}(t) \\
y_{2}(t)
\end{array}\right]=\left[\begin{array}{l}
A C E_{1}(t) \\
A C E_{2}(t)
\end{array}\right]=\mathbf{C} x(t)
$$

and

$$
A C E_{i}(t)=\Delta P_{\text {tie }}+B_{i} \Delta f_{i}
$$


where $y(t), A C E_{i}(t), B_{\mathrm{i}}, \Delta f_{\mathrm{i}}, \Delta P_{t i e}$ are output variable, error control in area $i$, bias frequency constant in area $i$, frequency deviation in area $i$, and deviation of inter-area tie-line power, respectively.

State-space matrices of LFC in (1)-(2) are defined as follow,

$$
\begin{aligned}
& {\left[\begin{array}{c}
\dot{x}_{1} \\
\dot{x}_{2} \\
\dot{x}_{3} \\
\dot{x}_{4} \\
\dot{x}_{5} \\
\dot{x}_{6} \\
\dot{x}_{7}
\end{array}\right]=\left[\begin{array}{c}
\Delta \dot{f}_{1} \\
\Delta \dot{P}_{m 1} \\
\Delta \dot{P}_{G 1} \\
\Delta \dot{P}_{t i e} \\
\Delta \dot{f}_{2} \\
\Delta \dot{P}_{m 2} \\
\Delta \dot{P}_{G 2}
\end{array}\right]=\left[\begin{array}{ccccccc}
a_{1,1} & \cdot & \cdot & \cdot & \cdot & \cdot & a_{1,7} \\
\cdot & \cdot & \cdot & \cdot & \cdot & \cdot & \cdot \\
\cdot & \cdot & & & \cdot & \cdot \\
\cdot & \cdot & & & \cdot & \cdot \\
\cdot & \cdot & & & \cdot & \cdot \\
\cdot & \cdot & \cdot & \cdot & \cdot & \cdot & \cdot \\
a_{7,1} & \cdot & \cdot & \cdot & \cdot & \cdot & a_{7,7}
\end{array}\right]\left[\begin{array}{c}
\Delta f_{1} \\
\Delta P_{m 1} \\
\Delta P_{G 1} \\
\Delta P_{t i e} \\
\Delta f_{2} \\
\Delta P_{m 2} \\
\Delta P_{G 2}
\end{array}\right]+\left[\begin{array}{cc}
b_{1,1} & b_{1,2} \\
\cdot & \cdot \\
\cdot & \cdot \\
\cdot & \cdot \\
\cdot & \cdot \\
\cdot & \cdot \\
b_{7,1} & b_{7,2}
\end{array}\right]\left[\begin{array}{l}
\Delta P_{c 1} \\
\Delta P_{c 2}
\end{array}\right]} \\
& +\left[\begin{array}{cc}
l_{1,1} & l_{1,2} \\
\cdot & \cdot \\
\cdot & \cdot \\
\cdot & \cdot \\
\cdot & \cdot \\
l_{7,1} & l_{7,2}
\end{array}\right]\left[\begin{array}{l}
\Delta P_{L 1} \\
\Delta P_{L 2}
\end{array}\right]
\end{aligned}
$$

where the matrix elements of $\mathbf{A}, \mathbf{B}, \mathbf{L}$, and $\mathbf{C}$ are provided as follow and other matrices components values unlisted in bellow are zero.

$$
\begin{aligned}
& a_{1,2}=-\frac{D_{1}}{M_{1}} ; \quad a_{1,2}=\frac{1}{M_{1}} ; \quad a_{1,3}=-\frac{1}{M_{1}} ; \quad a_{2,2}=-\frac{1}{T_{C H 1}} ; \quad a_{2,3}=\frac{1}{T_{C H 1}} \quad a_{3,1}=-\frac{1}{T_{g 1} \times R_{1}} ; \\
& a_{3,3}=-\frac{1}{T_{g 1}} ; a_{4,1}=T_{12} ; a_{4,5}=-T_{12} ; a_{5,4}=\frac{1}{M_{2}} ; a_{5,5}=-\frac{D_{2}}{M_{2}} ; a_{5,6}=\frac{1}{M_{2}} ; a_{6,6}=-\frac{1}{T_{C H 2}} \\
& ; a_{6,7}=\frac{1}{T_{C H 2}} ; a_{7,5}=-\frac{1}{T_{g 2} \times R_{2}} ; a_{7,7}=-\frac{1}{T_{g 2}} \\
& b_{3,1}=\frac{1}{T_{g 1}} ; \quad b_{7,2}=\frac{1}{T_{g 2}} \\
& l_{1,1}=-\frac{1}{M_{1}} ; \quad l_{5,2}=-\frac{1}{M_{2}} \\
& {\left[\begin{array}{l}
y_{1} \\
y_{2} \\
y_{3} \\
y_{4} \\
y_{5} \\
y_{6} \\
y_{7}
\end{array}\right]=\left[\begin{array}{ccccccc}
c_{1,1} & \cdot & \cdot & \cdot & \cdot & \cdot & 0 \\
\cdot & c_{2,2} & \cdot & \cdot & \cdot & \cdot & \cdot \\
\cdot & \cdot & & & & \cdot & \cdot \\
\cdot & \cdot & & & & \cdot & \cdot \\
\cdot & \cdot & & & & \cdot & \cdot \\
\cdot & \cdot & \cdot & \cdot & \cdot & c_{6,6} & \cdot \\
0 & \cdot & \cdot & \cdot & \cdot & \cdot & c_{7,7}
\end{array}\right]\left[\begin{array}{c}
\Delta f_{1} \\
\Delta P_{m 1} \\
\Delta P_{G 1} \\
\Delta P_{t i e} \\
\Delta f_{2} \\
\Delta P_{m 2} \\
\Delta P_{G 2}
\end{array}\right]}
\end{aligned}
$$

where $c_{1,1}, c_{2,2}, c_{3,3}, c_{4,4}, c_{5,5}, c_{6,6}$, and $c_{7,7}$ values are 1 . 


\section{B. LFC Equipped with PI Controller}

Due to the impact of disturbance to power system causes the system frequency downfall from its nominal value, the PI controller parameters consisting of proportional $\mathbf{K}_{P}$ and integral $\mathbf{K}_{I}$ gains are installed on LFC power system to restrain the system frequency to its nominal value by controlling the error control signal $A C E$ in area $i$ as depicted in Figure 2. In here, new variables $v(t)$ and $z(t)$ are added to control scheme in Figure 1 as variable states for PI controller gains $\mathbf{K}_{P}$ and $\mathbf{K}_{I}$, respectively. Block diagram for the implementation of PI controller on two-area LFC is described in Figure 2.

State-space models including variables of $v(\mathrm{t})$ dan $z(\mathrm{t})$ are provided in (7)-(8).

$\dot{x}_{\mathrm{N}}(\mathrm{t})=\mathbf{A}_{N} x_{N}(\mathrm{t})+\mathbf{B}_{N} u(\mathrm{t})+\mathbf{L}_{N} d(\mathrm{t})$

$\mathrm{y}_{\mathrm{N}}(\mathrm{t})=\mathrm{C}_{\mathrm{N}} \mathrm{x}_{\mathrm{N}}(\mathrm{t})$

where $\quad \mathrm{x}_{\mathrm{N}}(\mathrm{t})=\left[\begin{array}{l}\mathrm{x}(\mathrm{t}) \\ \mathrm{z}(\mathrm{t})\end{array}\right] ; \mathrm{y}_{\mathrm{N}}(\mathrm{t})=\left[\begin{array}{l}\mathrm{y}(\mathrm{t}) \\ \mathrm{z}(\mathrm{t})\end{array}\right] ; \quad \mathrm{z}(\mathrm{t})=\left[\begin{array}{l}\mathrm{z}_{1}(\mathrm{t}) \\ \mathrm{z}_{2}(\mathrm{t})\end{array}\right] ; \mathrm{v}_{l}(\mathrm{t})=A C E_{l}(\mathrm{t}) ; \quad v_{2}(\mathrm{t})=A C E_{2}(\mathrm{t})$

$z_{1}(\mathrm{t})=\int A C E_{1}(\mathrm{t}) d t ; z_{2}(\mathrm{t})=\int A C E_{2}(\mathrm{t}) d t$

$\mathrm{A}_{N}=\left[\begin{array}{cc}\mathrm{A} & 0 \\ \mathrm{C} & 0\end{array}\right] ; \mathrm{B}_{N}=\left[\begin{array}{c}\mathrm{B} \\ 0\end{array}\right] ; \mathrm{L}_{N}=\left[\begin{array}{c}\mathrm{L} \\ 0\end{array}\right] ; \mathrm{C}_{N}=\left[\begin{array}{cc}\mathrm{C} & 0 \\ 0 & I\end{array}\right]$

Control signal $\Delta P_{\mathrm{c}}$ can be written as follows,

$$
\left[\begin{array}{l}
\Delta P_{C 1} \\
\Delta P_{C 2}
\end{array}\right]=\left[\begin{array}{l}
u_{1} \\
u_{2}
\end{array}\right]=-\left[\begin{array}{cc}
k_{P 1} & 0 \\
0 & k_{P 2}
\end{array}\right]\left[\begin{array}{l}
v_{I}(\mathrm{t}) \\
v_{l}(\mathrm{t})
\end{array}\right]-\left[\begin{array}{c}
\Delta e_{1} \\
\Delta e_{2}
\end{array}\right]
$$

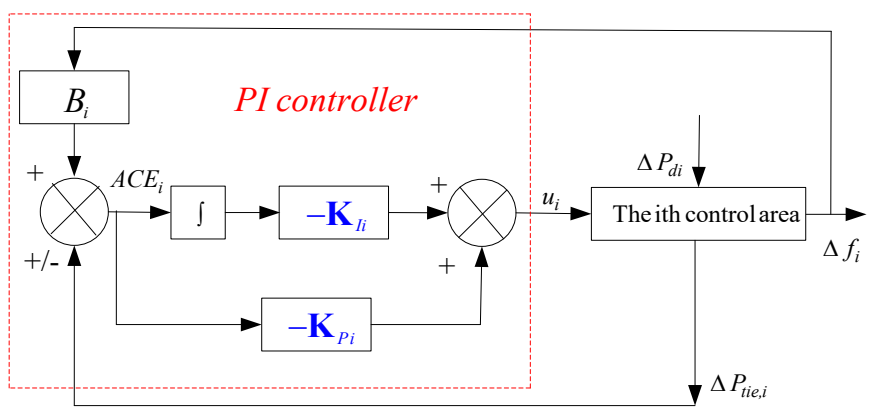

(a) PI controller applied on LFC in area $i$.

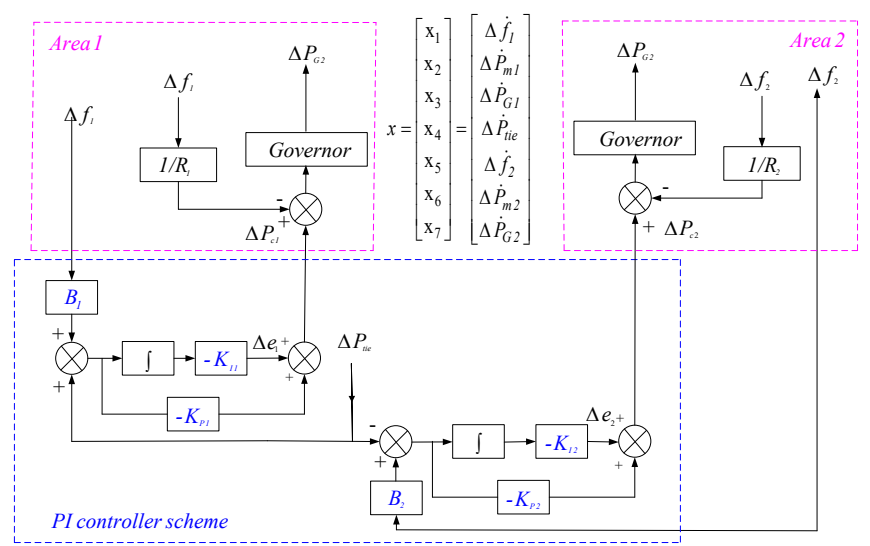

(b) PI controller employed on two-area LFC

Figure 2. The employment of a PI controller on LFC power system 
Equation (9) can be written as (10).

$$
\begin{aligned}
& {\left[\begin{array}{l}
\Delta P_{C 1} \\
\Delta P_{C 2}
\end{array}\right]=\mathrm{u}=-\mathbf{K}_{P}\left[\begin{array}{l}
v_{1}(\mathrm{t}) \\
v_{2}(\mathrm{t})
\end{array}\right]-\left[\begin{array}{cc}
k_{I 1} & 0 \\
0 & k_{I 2}
\end{array}\right]\left[\begin{array}{l}
z_{l}(\mathrm{t}) \\
z_{2}(\mathrm{t})
\end{array}\right]} \\
& \text { or } \\
& u=-\mathbf{K}_{P}\left[\begin{array}{l}
v_{l}(\mathrm{t}) \\
v_{2}(\mathrm{t})
\end{array}\right]-\mathbf{K}_{I}\left[\begin{array}{l}
z_{I}(\mathrm{t}) \\
z_{2}(\mathrm{t})
\end{array}\right]
\end{aligned}
$$

\section{LFC with Proposed Controller}

A hybrid of LQR optimal control with its feedback gain $\mathbf{K}_{O P}$ and PI controller applied as a proposed controller is utilized to increase the oscillation damping for two-area LFC model.

The proposed controller is depicted in Figure 3 and the control signal $\Delta P_{c i}$ in (10) can be written as follows.

$$
\left[\begin{array}{l}
\Delta P_{C 1} \\
\Delta P_{C 2}
\end{array}\right]=\left[\begin{array}{l}
u_{1} \\
u_{2}
\end{array}\right]=-\left[\begin{array}{cc}
k_{P 1} & 0 \\
0 & k_{P 2}
\end{array}\right]\left[\begin{array}{l}
v_{l}(\mathrm{t}) \\
v_{l}(\mathrm{t})
\end{array}\right]-\left[\begin{array}{l}
\Delta e_{1} \\
\Delta e_{2}
\end{array}\right]-\left[\begin{array}{l}
\sum_{j=1}^{7} \mathrm{x}_{j} k_{P 1 j} \\
\sum_{j=1}^{7} \mathrm{x}_{j} k_{P 2 j}
\end{array}\right]
$$

Equation (12) can be defined as in (13).

$$
\left[\begin{array}{l}
\Delta P_{C 1} \\
\Delta P_{C 2}
\end{array}\right]=\mathbf{u}=-\mathbf{K}_{P}\left[\begin{array}{l}
v_{1}(\mathrm{t}) \\
v_{2}(\mathrm{t})
\end{array}\right]-\left[\begin{array}{cc}
k_{I 1} & 0 \\
0 & k_{I 2}
\end{array}\right]\left[\begin{array}{l}
z_{l}(\mathrm{t}) \\
z_{2}(\mathrm{t})
\end{array}\right]-\mathbf{K}_{O P} x
$$

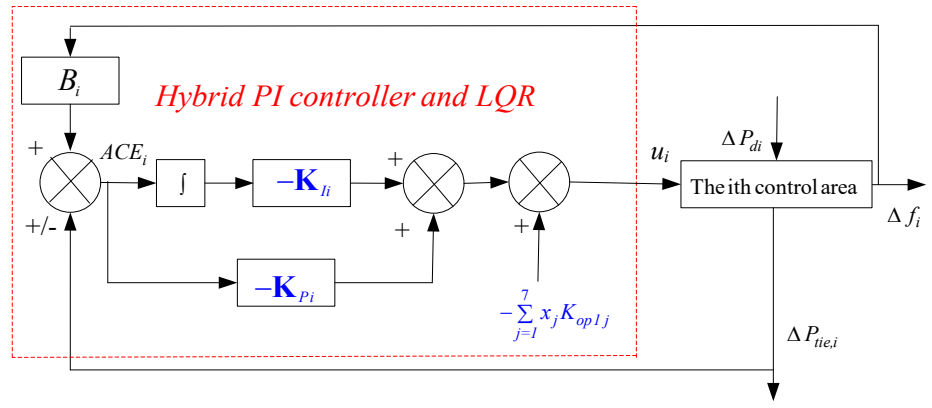

(a) Hybrid PI controller and LQR optimal control employed on LFC in area $i$.

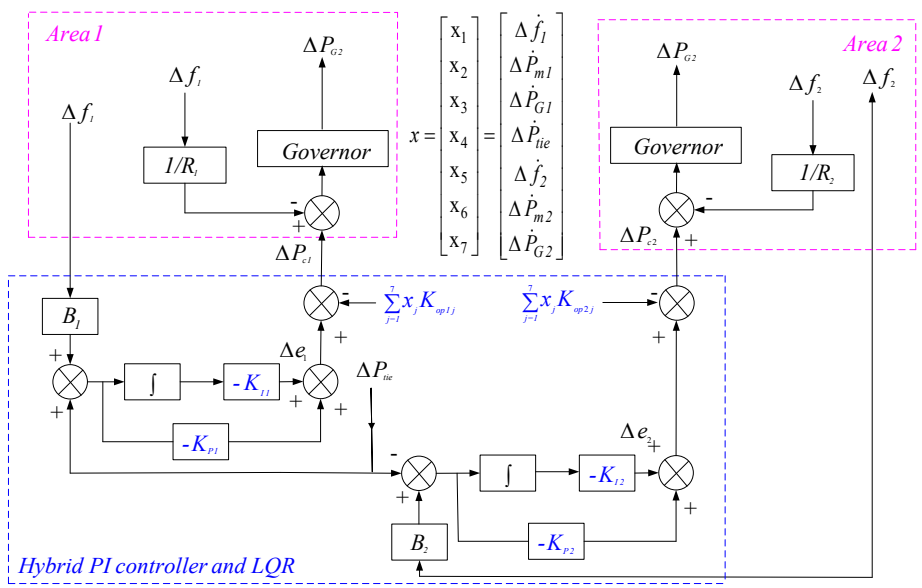

(b) Control scheme for PI controller and LQR optimal control for two-area LFC

Figure 3. The amalgamation of PI controller and LQR optimal control for LFC power system 
$u=-\mathbf{K}_{P}\left[\begin{array}{l}v_{l}(\mathrm{t}) \\ v_{2}(\mathrm{t})\end{array}\right]-\mathbf{K}_{I}\left[\begin{array}{l}z_{l}(\mathrm{t}) \\ z_{2}(\mathrm{t})\end{array}\right]-\mathbf{K}_{O P} x$

\section{Proposed Method}

In this section, a brief overview of the amalgamation of fuzzy PI controller and LQR optimal control optimized by artificial immune system via clonal selection is described.

A. Fuzzy PI

Fuzzy logic was proposed by Prof. Lotfi A. Zadeh in 1965 through his research work "Fuzzy Sets" on the Journal of Information and Control. The theory of fuzzy logic is inspired by the way of human response and cognition. Fuzzy logic can handle information emerging from computational response and cognition. The most popular and successful areas in the employment of fuzzy logic theory are fuzzy logic control (FLC) due to FLC can be an alternative controller in order to replace the conventional controller when the processes are too complex for analysis by conventional mathematical approaches. In this paper, Error $A C E_{i}(t)$ and error change $\triangle A C E_{i}(t)$ of control signals are utilized as FLC inputs, where $\triangle A C E_{i}(t)$ is $A C E_{i}(t)-A C E_{i}(t-1)$. While, FLC output is utilized to adjust the PI controller gains $\mathbf{K}_{P}$ and $\mathbf{K}_{I}$ adaptively. In designing of FLC model, the important procedure is how to determine the membership functions and control rules. In general, the membership functions and control rules are determined based on trial and error and designer experiences. The structure of FLC for tuning PI controller which is called fuzzy PI is described in Figure 4. In this study, the fuzzy PI shown in Figure 4 consists of four membership functions with two-input and two-output. Each membership function consists of seven triangular memberships, that are, LN (Large Negative), MN (Medium Negative), SN (Small Negative), VS (Very Small), SP (Small Positive), MP (Medium Positive), and LP (Large Positive). The MFs of fuzzy PI input and output variables are illustrated in Figure 5. The values of L for fuzzy PI input and output are set to $0.2,5$, and 2 , respectively. In this study, only the top points of triangular MFs are optimized. The designed fuzzy PI is installed in each area, successively, so that every area can determine its appropriate gain values individually. Fuzzy rules for fuzzy PI outputs $\mathbf{K}_{P i}$ and $\mathbf{K}_{I i}$ are the same as shown in Table 1 where 49 fuzzy rules are employed for gain scheduling of PI controller. FLC will automatically find the optimal gains of $\mathbf{K}_{P}$ and $\mathbf{K}_{I}$ in order to achieve a good response and steady-state accuracy.

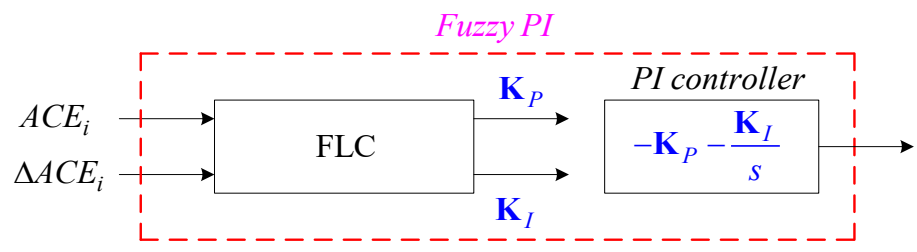

Figure 4. Structure of FLC for tuning PI controller

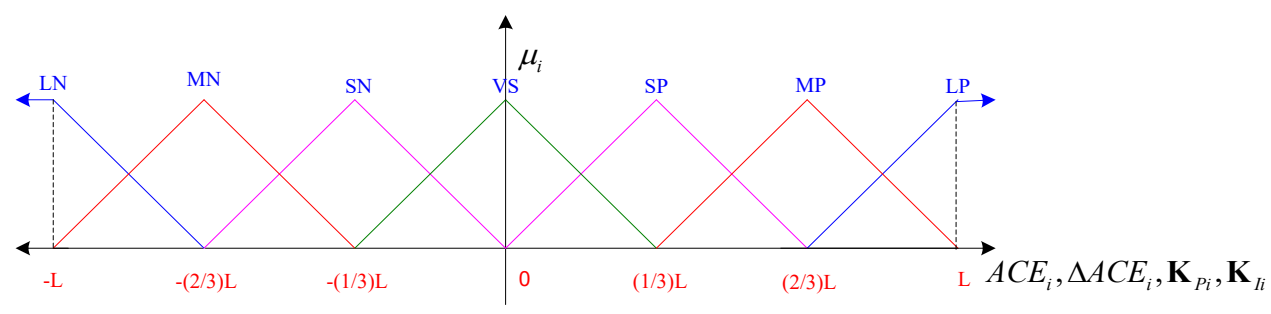

Figure 5. The MFs of fuzzy PI 
Table 1. Fuzzy Rules

\begin{tabular}{|c|c|c|c|c|c|c|c|}
\hline${ }_{A C E_{i}} \triangle A C E_{i}$ & $\mathrm{LN}$ & $\mathrm{MN}$ & SN & VS & SP & MP & LP \\
\hline LP & VS & SP & MP & LP & LP & LP & LP \\
\hline MP & $\mathrm{SN}$ & VS & SP & MP & MP & LP & LP \\
\hline SP & $\mathrm{MN}$ & SN & VS & SP & SP & MP & LP \\
\hline VS & $\mathrm{MN}$ & $\mathrm{MN}$ & SN & VS & SP & MP & MP \\
\hline SN & LN & $\mathrm{MN}$ & SN & SN & VS & SP & MP \\
\hline $\mathrm{MN}$ & LN & LN & $\mathrm{MN}$ & $\mathrm{MN}$ & SN & VS & SP \\
\hline $\mathrm{LN}$ & $\mathrm{LN}$ & $\mathrm{LN}$ & $\mathrm{LN}$ & $\mathrm{LN}$ & MN & $\mathrm{SN}$ & $\mathrm{VS}$ \\
\hline
\end{tabular}

Each fuzzy rule $i$ in the fuzzy PI is of the form :

If $A C E_{i}$ is $A_{i 1}$ and $\triangle A C E_{i}$ is $A_{i 2}$ then $\boldsymbol{K}_{P i}$ is $c_{i}$ and $\boldsymbol{K}_{I i}$ is $v_{i}$

where $A_{i l}, A_{i 2}, c_{i}$, and $v_{i}$ are membership functions.

Center of Area (COA) method is employed to defuze the fuzzy PI output as defined in (15)

$$
\mathbf{K}_{P i}=\frac{\sum_{\mathrm{i}=1}^{\mathrm{r}} \mathrm{c}_{\mathrm{i}} \mu_{\mathrm{i}}}{\sum_{\mathrm{i}=1}^{\mathrm{r}} \mu_{\mathrm{i}}}, \mathbf{K}_{I i}=\frac{\sum_{\mathrm{i}=1}^{\mathrm{r}} \mathrm{v}_{\mathrm{i}} \mu_{\mathrm{i}}}{\sum_{\mathrm{i}=1}^{\mathrm{r}} \mu_{\mathrm{i}}}
$$

where $\mu_{i}$ is the linguistic value of the fuzzy set variable $\mathrm{r}$ is a number of fuzzy rules.

\section{B. LQR Optimal Control}

Optimal control based LQR is a matter of practical control plant system where the function is to minimize the error signal in the plant system. The schematic diagram of LQR optimal control installed to the plant system is depicted in Figure $6 . \mathbf{K}_{o p}$ is a feedback gain where it should be obtained from the LQR optimal control approach in order to attain an appropriate control signal $u$.

The plant system is assumed as a linear time-invariant (LTI) system model which is presented in (7) and (8). An appropriate control signal based on LQR optimal control theory is computed as follows [9].

In order to solve the problem, a quadratic criterion is taken with its performance index where is defined as in (12).

$$
J\left(t_{0}\right)=\frac{1}{2} x^{T}(T) S(T) x(T)+\frac{1}{2} \int_{t_{0}}^{T}\left[x^{T}(t) \mathbf{Q} x(t)+u^{T}(t) \mathbf{R} u(t)\right] d t
$$

where $t_{0}$ is the initial condition of the system, $S(T) \geq 0$ (positive semi-definite), $\mathbf{Q} \geq 0$ (positive semi-definite), and $\mathbf{R}>0$ (positive definite) with the dimension $\mathbf{Q}^{n \times n}$ and $\mathbf{R}^{m x m}$, respectively. $\mathbf{Q}$ and $\mathbf{R}$ are weighting matrices of LQR optimal control.

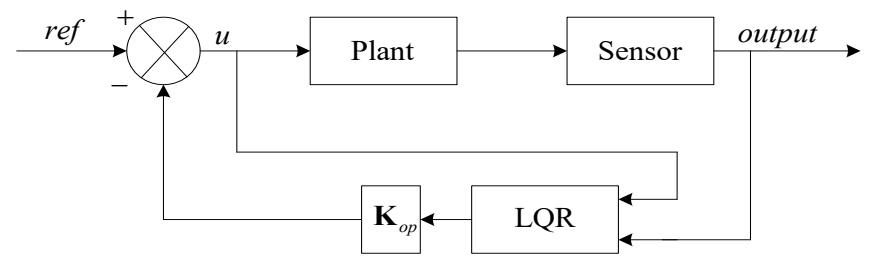

Figure 6. Block diagram of an optimal control system based on LQR optimal control

Equations (7) and (8) can be developed to solve the LQR optimal control problem in order to obtain feedback gain $\mathbf{K}_{O P}$. The performance index of LQR optimal control to be minimized can be written as in (13). 


$$
J(t)=\frac{1}{2} x^{T}(t) S(t) x(t)+\frac{1}{2} \int_{t}^{T}\left\|\mathbf{R}^{-1} \mathbf{B}^{T} S x+u\right\|_{R}^{2} d t
$$

The performance index on $[\mathrm{t}, \mathrm{T}]$ become,

$$
J(t)=\frac{1}{2} x^{T}(t) S(t) x(t)
$$

The solution of (14) is provided as follows:

$$
-\dot{S}=\mathbf{A}^{T} S+S \mathbf{A}-S \mathbf{B R}^{-1} \mathbf{B}^{T} S+\mathbf{Q}
$$

The LQR optimal control gain $\mathbf{K}_{O P}$ can be written as in (16).

$$
\begin{aligned}
& \mathbf{K}_{O P}(t)=\mathbf{R}^{-1} \mathbf{B}^{T} S(t), \in \mathfrak{R}^{\mathrm{mxn}} \\
& u(t)=-\mathbf{K}_{O P}(t) x(t)
\end{aligned}
$$

The state-space of the closed-loop system is

$$
\dot{x}(t)=\left(\mathbf{A}-\mathbf{B K}_{O P}\right) x
$$

In the closed-loop system matrix, riccati equation becomes Joseph stabilized formulation as follows

$$
-\dot{S}=\left(\mathbf{A}-\mathbf{B} \mathbf{K}_{O P}\right)^{T} S+S\left(\mathbf{A}-\mathbf{B} \mathbf{K}_{O P}\right)+\mathbf{K}_{O P}{ }^{T} \mathbf{R} \mathbf{K}_{O P}+\mathbf{Q}
$$

In general, using a trial-and-error method for (12)-(18) are computed until a satisfactory index value $J$ is obtained.

\section{Artificial Immune System (AIS)}

Artificial immune system (AIS) is a kind of meta-heuristic algorithm inspired by a human immune system. The function of immune system is to defend the human body from foreign organisms. The capability of immune system is to distinguish between the normal components of our organism and alien material where leads to endangering the human body. The alien organism is called an antigen. While, the molecules called antibodies play important role in immune system response. An immune system reaction is specific to a certain alien organism (antigen). When an antigen is known, those antibodies that best recognize an antigen will proliferate by replicating. This process is called clonal selection principle. Figure 7 describes the principle of AIS via clonal selection.

The procedures in clonal selection composed of three features are provided as follow:

- The new cells which are submitted to chromosomal mutation chemical mechanism are verily duplicated of their parents.

- Evacuation of newly differentiated lymph cells bringing self-reactive sensory receptors.

- Development and differentiation of contact of mature cells with antigens.

When an antibody is strongly matched to antigen, a subpopulation of bone marrow cells derived (B lymphocytes) will respond by yielding an antibody $(\mathrm{Ab})$. Each confidential cell has one kind of antibody which is relatively definite for the antigen. An antigen is recognized by an antibody with a certain affinity (degree of match), the B lymphocytes will be driven to proliferate (divide) and finally arise into a terminal (non-dividing) antibody-secreting cells, called a plasma cell. Proliferation of the B lymphocytes is a mitotic process with the help of the cells to split themselves, generating a set of clones identical to the parent cell. The proliferation stage is proportional to the affinity degree, that is, the higher affinity levels of B lymphocyte. The more of them will be readily selected for cloning and copied in huge numbers. In addition to proliferating and maturing into plasma cells, the immune cells can distinguish into long-lived memory cells. Memory cells dispense through the blood, lymph, and tissues and when exposed to the second antigenic stimulus they initiate into large immune cells (lymphocyte) adequate of yielding high-affinity antibody and the certain antigen that once stimulated the primary reaction. The explanations of AIS via clonal selection parameters are given in Table 2. 


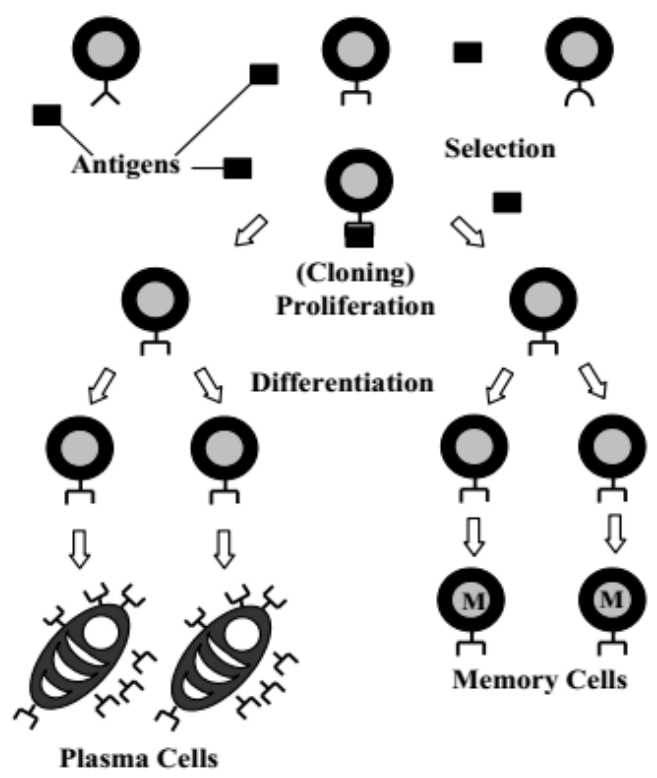

Figure 7. Artificial immune system (AIS) via clonal selection

Table 2. AIS via Clonal Selection Description

\begin{tabular}{|c|l|}
\hline Parameter & \multicolumn{1}{|c|}{ Description } \\
\hline P & Antibodies repertoire \\
\hline N & A number of antibodies \\
\hline N & Antibodies will be chosen for cloning \\
\hline L & Bit string length for every antibody \\
\hline Dc & A number of clones yielded by every chosen antibody \\
\hline Stop condition & $\begin{array}{l}\text { A random number of antibodies to insert at the end of every } \\
\text { generation. Best antibodies replace the lowest affinity antibodies d in } \\
\text { the repertoire }\end{array}$ \\
\hline Affinity & Maximum generation \\
\hline Clone & Solution evolution \\
\hline Hypermutate & $\begin{array}{l}\text { Moplication of chosen bit string } \\
\text { bit or multiple bit) is governed by an affinity proportionate probability } \\
\text { distribution }\end{array}$ \\
\hline
\end{tabular}

The pseudocode of AIS via clonal selection is expressed as follows [18].

$\mathrm{P} \leftarrow \operatorname{rand}(\mathrm{N}, \mathrm{L})$

While Not Stop condition Do

For Each $\mathrm{p}$ of P Do // presentation

affinity(p)

End For

$\mathrm{P} 1 \leftarrow \operatorname{select}(\mathrm{P}, \mathrm{n})$

clonal selection

For Each p1 of P1 Do // clonal expansion

$\mathrm{C} \leftarrow$ clone $(\mathrm{p} 1)$

End For

For Each c of C Do //affinity maturation

hypermutation(c)

End For 
For Each c of C Do // presentation affinity(c)

End for

$\mathrm{P} \leftarrow$ insert $(\mathrm{C}, \mathrm{n}) / /$ greedy selection

$\operatorname{Pr} \leftarrow$ rand $(\mathrm{d}, \mathrm{L})$

$\mathrm{P} \leftarrow$ replace $(\mathrm{P} . \mathrm{D}$. Pr) // random replacement End While

\section{Implementation of Proposed Method}

In this section, the employment of AIS via clonal selection in order to optimize the parameters of fuzzy PI and LQR optimal control is described. The control scheme of fuzzy PI and LQR optimal control for LFC power system is depicted in Figure 8. AIS via clonal selection is utilized as a tool to adjust the MF of fuzzy PI and weighting matrices $\mathbf{Q}$ and $\mathbf{R}$ of LQR optimal control automatically in order to maintain the frequency of LFC due to disturbance is occurred, where depicted in Figure 9. The flowchart of the proposed method is illustrated in Figure 10.

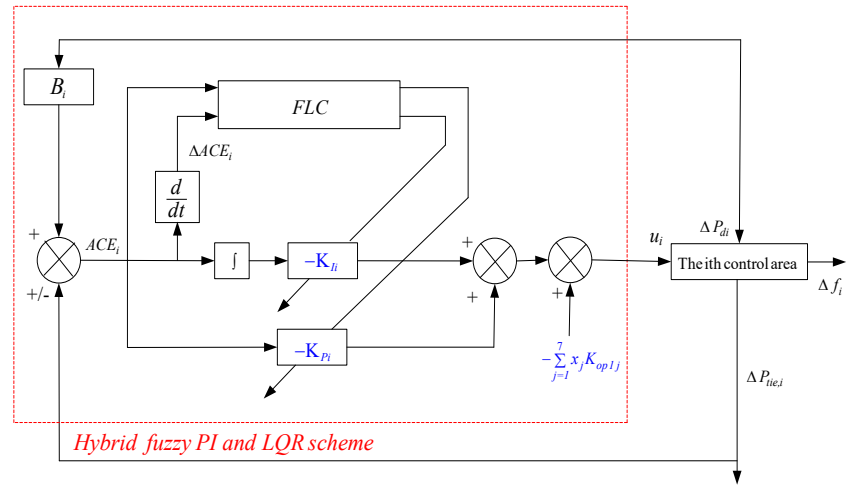

Figure 8. The amalgamation of fuzzy PI and LQR optimal control

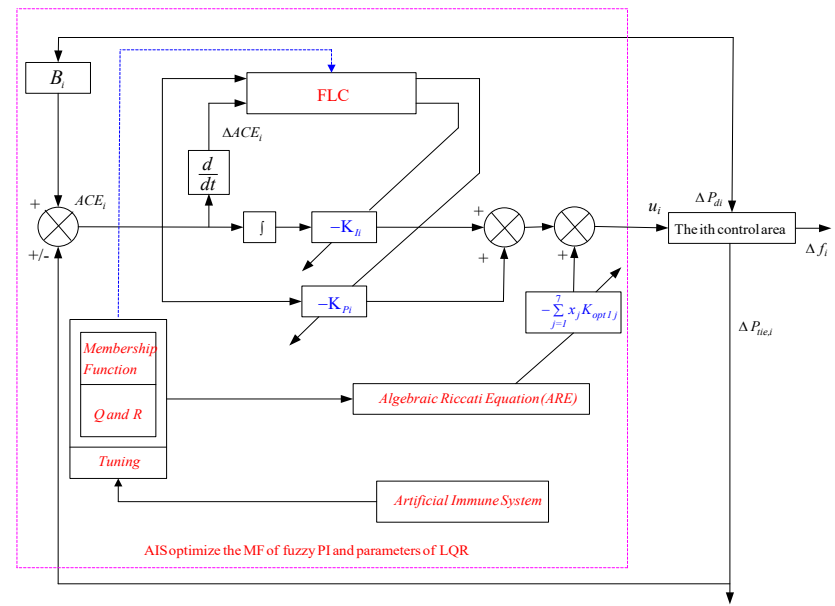

Figure 9. The schematic diagram of proposed method 


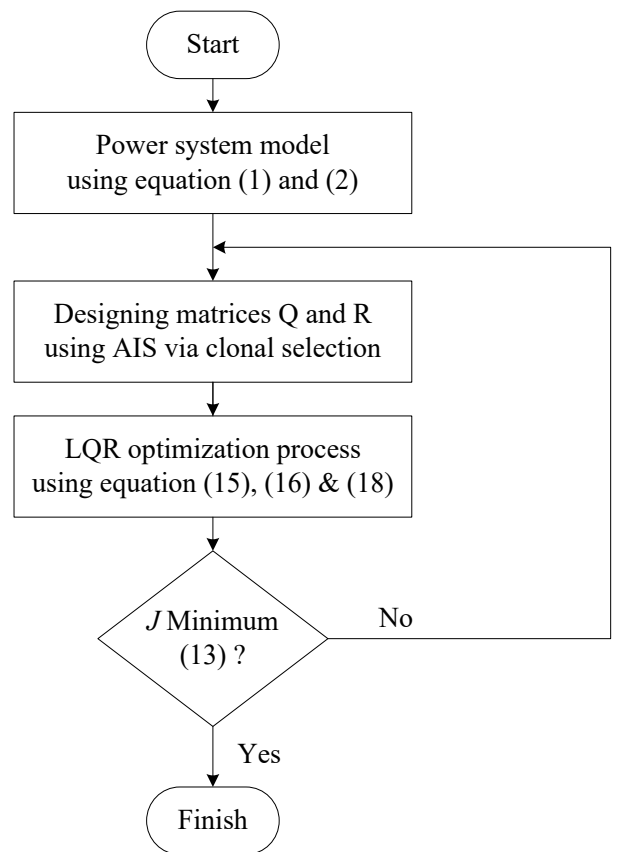

Figure 10. Flowchart of the proposed method follows:

The computational process of the proposed approach depicted in Figure 10 is described as

a. Generate an initial population of antibody: Randomly generate initial antibody in population

b. Calculate the objective function (affinity): Performance index utilized as objective function is expressed as follows.

$\operatorname{Min} J, J=\left(\int_{0}^{t_{f}}\left(A C E_{1}(t)^{2}+A C E_{2}(t)^{2}\right) d t\right)+\frac{1}{2} x^{T}(t) S(t) x(t)$

subjected to:

$$
\begin{aligned}
& \mathrm{NL}_{\text {min }} \leq \mathrm{NL} \leq \mathrm{NL}_{\text {max }}, \mathrm{NM}_{\text {min }} \leq \mathrm{NM} \leq \mathrm{NM}_{\text {max }}, \mathrm{NS}_{\text {min }} \leq \mathrm{NS} \leq \mathrm{NS}_{\text {max }}, \\
& \mathrm{VS}_{\text {min }} \leq \mathrm{VS} \leq \mathrm{VS}_{\text {max }}, \mathrm{PS}_{\text {min }} \leq \mathrm{PS} \leq \mathrm{PS}_{\text {max }}, \mathrm{PM}_{\text {min }} \leq \mathrm{PM} \leq \mathrm{PM}_{\max }, \\
& \mathrm{PB}_{\text {min }} \leq \mathrm{PB} \leq \mathrm{PB}_{\text {max }}, \mathbf{Q}_{\text {min }} \leq \mathbf{Q} \leq \mathbf{Q}_{\text {max }}, \mathbf{R}_{\text {min }} \leq \mathbf{R} \leq \mathbf{R}_{\text {max }},
\end{aligned}
$$

where the MF bounds of $A C E_{i}$ and $\triangle A C E_{i}$ are $\operatorname{LN}\{(-0.20)-(-0.133)\}, \operatorname{MN}\{(-0.133)-$ $(-0.0667)\}, \operatorname{SN}\{(-0.0667)-0\}, \operatorname{VS}\{0\}, \operatorname{SP}\{0-0.0667\}, \operatorname{MP}\{0.0667-0.133\}$, and $\operatorname{LP}\{0.133 \sim 0.2\}$. The MF margins for $\mathbf{K}_{P i}$ are $\operatorname{LN}\{(-5)-(-3.33)\}, \operatorname{MN}\{(-3.33)-(-$ $1.667)\}, \operatorname{SN}\{(-1.667)-0\}, \operatorname{VS}\{0\}, \operatorname{SP}\{0-1.667\}, \operatorname{MP}\{1.667-3.33\}$, and $\operatorname{LP}\{3.33-5\}$. The MF limits of

$\mathbf{K}_{I i}$ are $\operatorname{LN}\{(-2)-(-1.33)\}, \operatorname{MN}\{(-1.33)-(-0.667)\}, \operatorname{SN}\{(-0.667)-0\}, \operatorname{VS}\{0\}, \operatorname{SP}\{0-$ $0.667\}, \operatorname{MP}\{0.667-1.33\}$, and LP $\{1.33-2\}$. The bounds of $\mathbf{Q}$ and $\mathbf{R}$ matrices $\mathbf{Q}_{\min }$, $\mathbf{Q}_{\max }, \mathbf{R}_{\min }, \mathbf{R}_{\max }$ are 0, 100, 0, and 10, respectively.

c. Select the best antibody by measuring their affinities: Affinity is computed by performance index in step $b$. Antibody with high affinity is the best antibody in this algorithm.

d. Clone best antibody: Antibody with high affinity in population has higher probabilities will be cloned. 


\begin{tabular}{|c|c|c|c|c|c|c|}
\hline $\mathrm{LN}$ & $\mathrm{MN}$ & $\mathrm{SN}$ & $\mathrm{VS}$ & $\mathrm{SP}$ & $\mathrm{MP}$ & $\mathrm{LP}$ \\
\hline
\end{tabular}

Antibodies structures for MFs of fuzzy PI input and output variables $\left[A C E_{i}, \triangle A C E_{i}, \mathbf{K}_{P i}, \mathbf{K}_{I i}\right]$

\begin{tabular}{|c|c|c|c|c|c|c|c|c|}
\hline $\mathrm{q}_{1,1}$ & $\mathrm{q}_{2,2}$ & $\mathrm{q}_{3,3}$ & $\mathrm{q}_{4,4}$ & $\mathrm{q}_{5,5}$ & $\mathrm{q}_{6,6}$ & $\mathrm{q}_{7,7}$ & $\mathrm{q}_{8,8}$ & $\mathrm{q}_{9,9}$ \\
\hline
\end{tabular}

Antibodies structures for matrices $\mathbf{Q}$

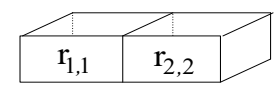

Antibodies structures for matrices $\mathbf{R}$

Figure 11. Antibodies structures for optimizing MFs of fuzzy PI and parameters of LQR optimal control

e. Take into account the population of clones to an affinity maturation scheme: Antibody with lower affinity has higher probabilities will be hyper-mutated.

f. Re-select:

Each antibody is re-select based on step b.

g. Replace a new antibody to previous antibody:

An antibody with a lower affinity will be replaced.

MFs of fuzzy PI and weighting matrices $\mathbf{Q}$ and $\mathbf{R}$ of LQR optimal control are encoded into antibodies of AIS via clonal selection. The antibodies structures of AIS consist of MF of fuzzy PI and the weighting matrices $\mathbf{Q}$ and $\mathbf{R}$ as depicted in Figure 11.

A number of genes in antibodies for fuzzy PI membership function depend on the number of top points of fuzzy MF from the input and output variables. Further, a number of genes for weighting matrices $\mathrm{Q}$ and $\mathrm{R}$ influenced by the number of state variables $\left[\Delta f_{1}, \Delta P_{m l}, \Delta P_{G l}, \Delta P_{t i e}\right.$, $\left.\Delta f_{2}, \Delta P_{m 2}, \Delta P_{G 2}, \Delta z_{1}, \Delta z_{2}\right]$ and input variables $\left[\Delta P_{\mathrm{c} 1}, \Delta P_{\mathrm{c} 2}\right]$, respectively.

\section{Simulation Results and Discussions}

In this section, the simulation results of proposed method in order to improve the dynamic performance of two-area LFC model are provided, where all simulations are carried out using Intel Core i7 $2.20 \mathrm{GHz}, 8 \mathrm{~GB}$ of RAM Memory. MATLAB software platform is utilized for the implementation of proposed approach. Two-area load frequency control (LFC) model utilized as a test system to examine the robustness of the proposed method is taken from [29]. The data for two-area LFC power system are collected from [30]. Those data are summarized in Tables 3 and 4 including PI controller parameters. AIS parameters used in this study are listed in Table 5, where cloning is employed for 10 antibodies from 100 antibodies, and mutation is also conducted to 100 antibodies that have a different affinity. A small value of probability for mutation is given for antibodies that have high-affinity values. In the design process and simulation studies, a 0.1 p.u step load disturbance is applied to area 1. The convergence curve of AIS via clonal selection is illustrated in Figure 12.

Table 3. Two-Area LFC Data

\begin{tabular}{|c|c|c|c|}
\hline Parameters & Values & Parameters & Values \\
\hline $\mathrm{M}_{1}$ & $6.0 \mathrm{~s}$ & $\mathrm{~T}_{\mathrm{CH} 1}$ & $0.35 \mathrm{~s}$ \\
\hline $\mathrm{M}_{2}$ & $8.0 \mathrm{~s}$ & $\mathrm{~T}_{\mathrm{CH} 2}$ & $0.4 \mathrm{~s}$ \\
\hline $\mathrm{R}_{1}$ & $2.4 \mathrm{~Hz} / \mathrm{p} . \mathrm{u}$ & $\mathrm{T}_{\mathrm{g} 1}$ & $0.04 \mathrm{~s}$ \\
\hline $\mathrm{R}_{2}$ & $3.2 \mathrm{~Hz} / \mathrm{p} . \mathrm{u}$ & $\mathrm{T}_{\mathrm{g} 2}$ & $0.5 \mathrm{~s}$ \\
\hline $\mathrm{B}_{1}$ & $\left(1 / \mathrm{R}_{1}\right)+\mathrm{D}_{1} \mathrm{p} . \mathrm{u} / \mathrm{Hz}$ & $\mathrm{B}_{2}$ & $\left(1 / \mathrm{R}_{2}\right)+\mathrm{D}_{2} \mathrm{p} . \mathrm{u} / \mathrm{Hz}$ \\
\hline $\mathrm{T}$ & $0.62 \mathrm{p} . \mathrm{u}$ & \multicolumn{3}{|l}{} \\
\hline
\end{tabular}


Table 4. PI Controller Data

\begin{tabular}{|c|c|}
\hline Parameters & Values \\
\hline $\mathbf{K}_{P 1}$ & 0.8 \\
\hline $\mathbf{K}_{P 2}$ & 0.9 \\
\hline $\mathbf{K}_{I 1}$ & 0.3 \\
\hline $\mathbf{K}_{I 2}$ & 0.25 \\
\hline
\end{tabular}

Table 5. Parameters of AIS

\begin{tabular}{|c|l|c|}
\hline No & \multicolumn{1}{|c|}{ Parameters } & Value \\
\hline 1 & Number of Generations & 70 \\
\hline 2 & Number of Antibodies & 100 \\
\hline 3 & Number of Genes & 67 \\
\hline 4 & Number of Clones & $10 / \mathrm{Ab}$ \\
\hline 5 & Probabilities of Mutations & {$\left[\begin{array}{lllll}0.10 .2 & 0.30 .40 .5 & 0.6 & 0.70 .8 & 0.9\end{array}\right]$} \\
\hline
\end{tabular}

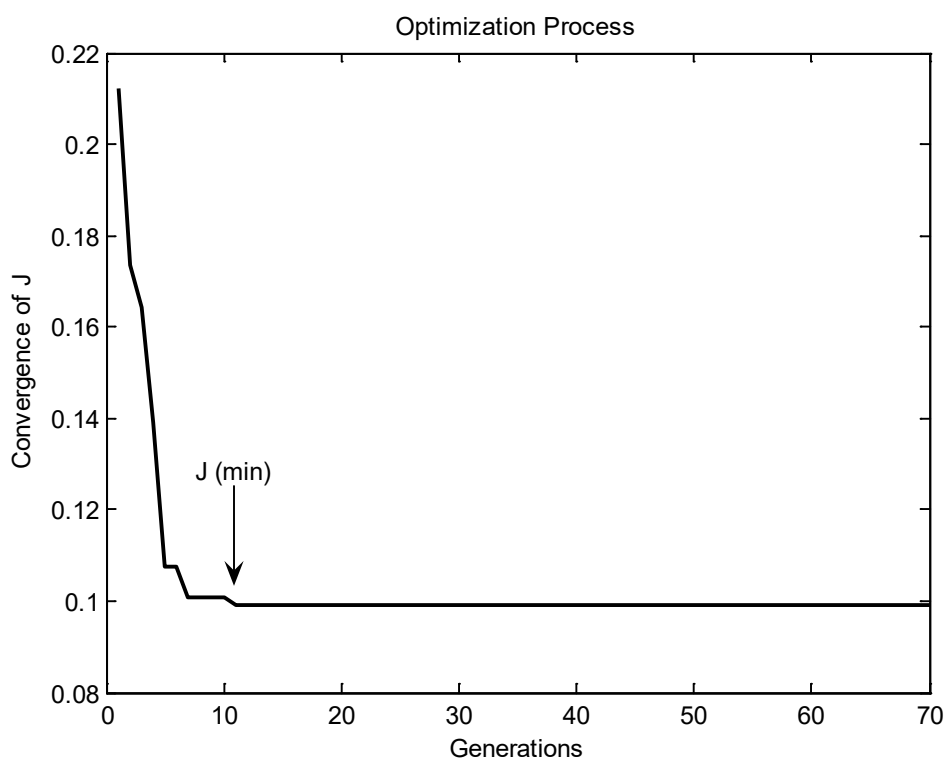

Figure 12. Convergence graph of AIS via clonal selection

The AIS via clonal selection initiates its affinity value from 0.218 and decrease to 0.1 at the $11^{\text {th }}$ generation which means that the proposed AI method had reached convergence value at the $11^{\text {th }}$ generation. Thus, the minimum $J$ value is 0.1 . Notably, the convergence has a smooth nature to attain the best affinity value. Although the maximum generation was set as 70, the AIS via clonal selection had reached earlier than the maximum generation.

The fuzzy membership function values of fuzzy PI controller obtained by AIS optimization for area 1 are provided as follow,

1. $A C E_{1}\{\mathrm{LN}=-0.138, \mathrm{MN}=-0.084, \mathrm{SN}=-0.061, \mathrm{VS}=0, \mathrm{SP}=0.055, \mathrm{MP}=0.12$, and $\mathrm{LP}=$ $0.158\}$

2. $\triangle A C E_{1}\{\mathrm{LN}=-0.147, \mathrm{MN}=-0.114, \mathrm{SN}=-0.042, \mathrm{VS}=0, \mathrm{SP}=0.059, \mathrm{MP}=0.078$, and $\mathrm{LP}$ $=0.169\}$

3. $\mathbf{K}_{P I}\{\mathrm{LN}=-3.88, \mathrm{MN}=-3.302, \mathrm{SN}=-0.69, \mathrm{VS}=0, \mathrm{SP}=0.579, \mathrm{MP}=2.229$, and $\mathrm{LP}=3.34$ \}

4. $\mathbf{K}_{I I}\{\mathrm{LN}=-1.977, \mathrm{MN}=-1.188, \mathrm{SN}=-0.5109, \mathrm{VS}=0, \mathrm{SP}=0.6205, \mathrm{MP}=1.163$, and $\mathrm{LP}=$ $1.35\}$ 
While fuzzy membership function values of fuzzy PI controller for area 2 obtained by AIS optimization are defined as follow,

1. $A C E_{2}\{\mathrm{LN}=-0.158, \mathrm{MN}=-0.1, \mathrm{SN}=-0.057, \mathrm{VS}=0, \mathrm{SP}=0.023, \mathrm{MP}=0.11$, and $\mathrm{LP}=$ $0.164\}$

2. $\triangle A C E_{2}\{\mathrm{LN}=-0.144, \mathrm{MN}=-0.091, \mathrm{SN}=-0.029, \mathrm{VS}=0, \mathrm{SP}=0.039, \mathrm{MP}=0.116$, and $\mathrm{LP}$ $=0.1733\}$

3. $\mathbf{K}_{P 2}\{\mathrm{LN}=-4.38, \mathrm{MN}=-2.226, \mathrm{SN}=-0.791, \mathrm{VS}=0, \mathrm{SP}=0.444, \mathrm{MP}=2.878$, and $\mathrm{LP}=$ $3.618\}$

4. $\mathrm{K}_{I 2}\{\mathrm{LN}=-1.376, \mathrm{MN}=-0.753, \mathrm{SN}=-0.282, \mathrm{VS}=0, \mathrm{SP}=0.262, \mathrm{MP}=1.149$, and $\mathrm{LP}=$ $1.708\}$

The optimal values of weighting matrices $\mathbf{Q}$ and $\mathbf{R}$ obtained from optimization process result are given as follow,

$\mathbf{Q}=\left[\begin{array}{lll}16.3983 & 72.837507014 .881416 .015626 .351822 .63970\end{array}\right], \mathbf{R}=\left[\begin{array}{ll}1 & 1\end{array}\right]$.

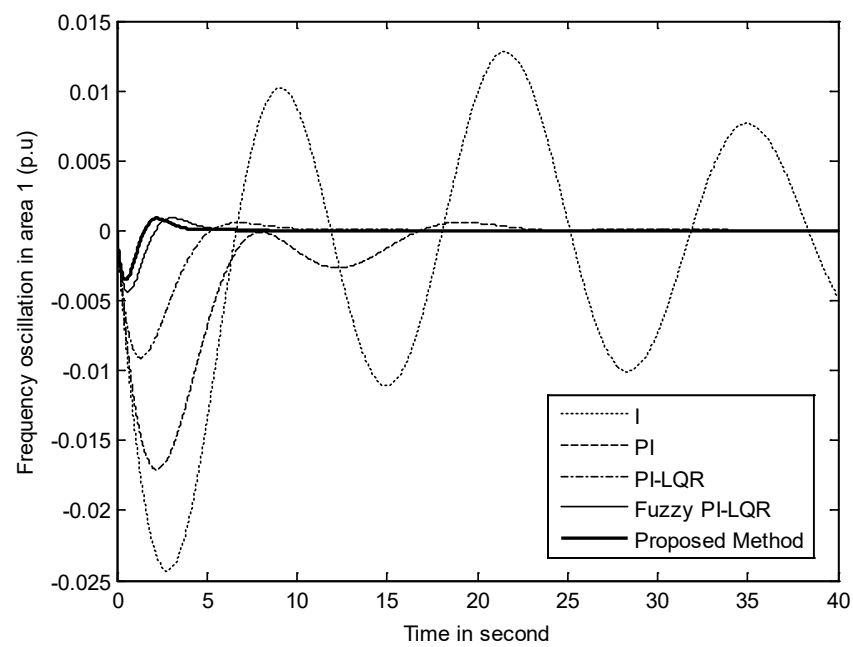

Figure 13. Frequency deviation at area 1

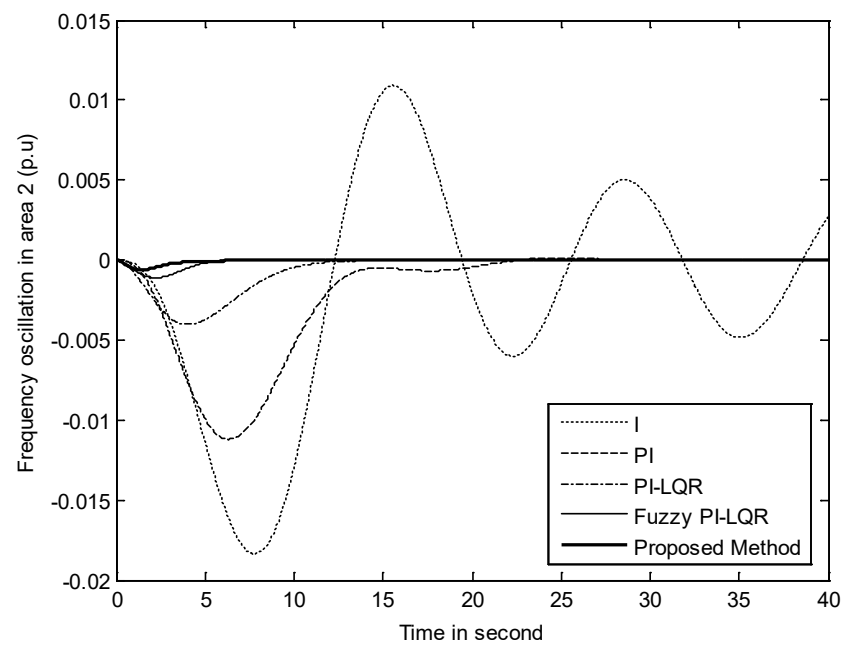

Figure 14. Frequency deviation at area 2 


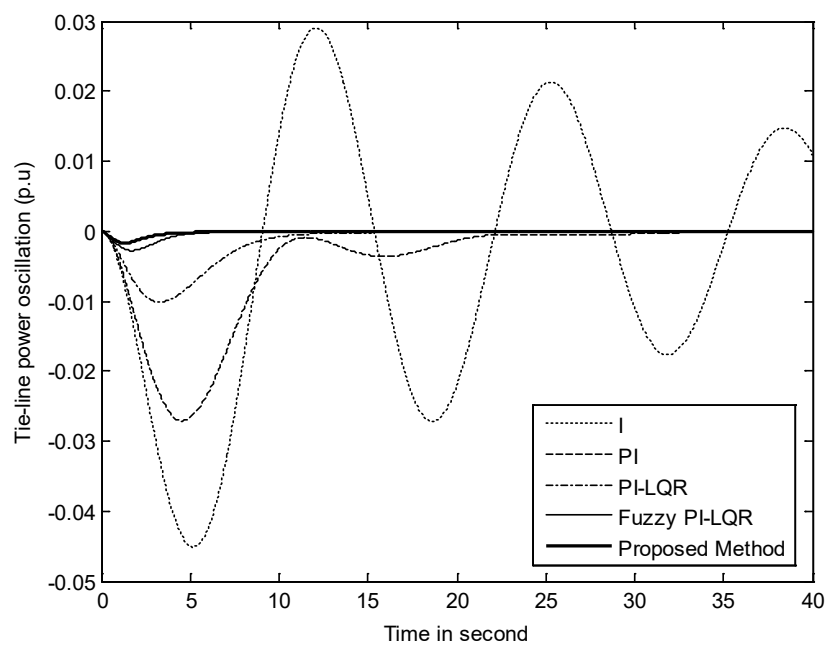

Figure 15. Tie-line power

The comparisons of the proposed method with other techniques such as I controller, PI controller, PI-LQR, fuzzy PI-LQR) in order to damp the frequency oscillation on area 1, frequency oscillation on area 2, and tie-line power are depicted in Figs. 13-15. The overshoot and settling time values in Figs. 13-15 are provided in Tables 6 and 7.

From Figure 13 and Table 6, it could be seen that the proposed approach has a rigorously smaller overshoot for frequency deviation in area 1 than that obtained by other techniques. The proposed method could decrease the overshoot of about $85 \%$ compared to the I controller, while the PI controller, PI-LQR, and fuzzy PI-LQR could decrease the overshoot around 29,8\%, $62.5 \%$, and $81.9 \%$, respectively. In terms of settling time values as seen in Figure 13 and Table 7 , the proposed approach could compress the settling time faster than other method utilized in this paper as of 8.64 seconds compared to the I controller. The proposed technique could bring back the frequency at area 1 to its nominal value after disturbance about $94.9 \%$ faster than the I controller. While, the PI controller, PI-LQR, and fuzzy PI-LQR could compress the settling time in $80 \%, 89.6 \%$, and $93.2 \%$ quicker than the I controller, respectively.

To illustrate the superiority of the proposed method to damp the frequency deviation on area 2, the overshoot and settling time values as depicted in Figure 14 and Tables 6-7 are analyzed. From Figure 14 and Tables 6-7, the proposed method could reduce the overshoot and settling time values as of $96.7 \%$ and $93.9 \%$ compared to the I controller. Other techniques such as the PI controller, PI-LQR, and fuzzy PI-LQR could alleviate overshoot around 39\%, 78.2\%, and $94.2 \%$, respectively. Whereas, in the viewpoint of settling time value, the PI controller, PI-LQR, and fuzzy PI-LQR provide a time alleviation around of $83.6 \%, 89.7$, and $92.2 \%$ compared to the I controller.

When the disturbance is applied to LFC, the tie-line power is also oscillating as is the frequency on area 1 and area 2. As seen in Figure 15 and Tables 6-7, the proposed approach could damp the overshoot of tie-line power about $96.4 \%$ and reduce the settling time around 94.1\% compared to the I controller. On the contrary, the overshoot of tie-line power could be reduced by the PI controller, PI-LQR, and fuzzy PI-LQR as of $39.7 \%, 77.5 \%, 93.8 \%$ which are better than the I controller. Additionally, the settling time values that could be achieved by the PI controller, PI-LQR, and fuzzy PI-LQR are $81.7 \%, 88.3 \%$, and $93.4 \%$ better than the I controller. 
Table 6. Overshoot value of two-area LFC

\begin{tabular}{|c|c|c|c|}
\hline & Integral Controller & PI Controller & PI-LQR \\
\hline$\Delta f_{1}$ & -0.02423 & -0.01705 & -0.009098 \\
\hline$\Delta f_{2}$ & -0.01837 & -0.01119 & -0.004014 \\
\hline$\Delta P_{\text {tie }}$ & -0.04487 & -0.02704 & -0.01011 \\
\hline & Fuzzy PI-LQR & \multicolumn{2}{|c|}{ Proposed Method } \\
\hline$\Delta f_{1}$ & -0.004369 & \multicolumn{2}{|c|}{-0.003465} \\
\hline$\Delta f_{2}$ & -0.00106 & \multicolumn{2}{|c|}{-0.0006066} \\
\hline$\Delta P_{\text {tie }}$ & -0.002765 & \multicolumn{2}{|c|}{-0.001627} \\
\hline
\end{tabular}

Table 7. Settling time value of two-area LFC

\begin{tabular}{|c|c|c|c|}
\hline & Integral Controller & PI Controller & PI-LQR \\
\hline$\Delta f_{1}$ & 169.6 & 33.06 & 17.66 \\
\hline$\Delta f_{2}$ & 172.6 & 28.24 & 21.56 \\
\hline$\Delta P_{\text {tie }}$ & 185.2 & 33.93 & \multicolumn{2}{|c|}{ Proposed Method } \\
\hline & Fuzzy PI-LQR & \multicolumn{2}{|c|}{8.64} \\
\hline$\Delta f_{1}$ & 11.46 & \multicolumn{2}{|c|}{10.36} \\
\hline$\Delta f_{2}$ & 13.43 & 10.91 \\
\hline$\Delta P_{\text {tie }}$ & 12.22 & \multicolumn{2}{|c|}{} \\
\hline
\end{tabular}

The proposed method has the best performance in control and damping of frequency and tie-line power in all responses where the frequency deviations and inter-area tie-line power quickly driven back to their nominal values. While, the system with an integral controller has the worst performance since it uses a conventional approach to obtain feedback gain to produce signal control of the system. When the control input has a good response, less overshoot, and faster settling time then the response of the system will be as good as the control input.

\section{Conclusion}

In this paper, a new control design approach based on fuzzy PI and LQR optimal control for load frequency control (LFC) on a two-area power system network has been presented. The efficacy of LFC control method to maintain the frequency oscillation due to load change assumed as a disturbance was examined. The employment of AIS via clonal selection to obtain the optimal membership function of fuzzy PI and LQR optimal control parameters was presented. Although the trial-error method (TEM) is very simple in order to determine the MF of fuzzy PI and LQR optimal control parameters, it is difficult to obtain their optimal control parameters. Also, it takes a long time to choose the best of their control parameters. Thus, the merit of the proposed method is that it can adjust automatically their control elements when there is a load change occurred on LFC power system model. Simulation results show that the performance of proposed controller is superior to the other controllers in terms of settling time, overshoot, and robustness under disturbance.

\section{Acknowledgment}

The author deeply thanks the anonymous reviewers for their valuable comments.

\section{References}

[1]. P. Kundur P., Power system stability and control, McGraw-Hill, Inc., 1994.

[2]. R. Shankar, K. Chatterjee, and T. K. Chatterjee, "A control strategy for load frequency control coordinating economic load dispatch \& load forecasting via kalman filter", International Journal on Electrical Engineering and Informatics, Vol. 4, No. 3, pp. 495$507,2012$. 
[3]. D. Lakshmi, A. Peer Fathima, and R. Muthu, "Simulation of the two-area deregulated power system using particle swarm optimization", International Journal on Electrical Engineering and Informatics, Vol. 8, No. 1, pp. 93-107, 2016.

[4]. N. Jalali, H. Razmi, and H. D. Mojarrad, "Optimized fuzzy self-tuning PID controller design based on tribe-DE optimization algorithm and rule weight adjustment method for load frequency control of interconnected multi-area power systems", Applied Soft Computing Journal, Vol. 93, pp. 1-19, 2020.

[5]. H. M. Hasanien and A. A. El-Fergany, "Salp swarm algorithm-based optimal load frequency control of hybrid renewable power systems with communication delay and excitation cross-coupling effect", Electric Power Systems Research, Vol. 176, pp. 1-10, 2019.

[6]. S. M. Nosratabadi, M. Bornapour, and M. A. Gharaei, "Grasshopper optimization algorithm for optimal load frequency control considering predictive functional modified PID controller in restructured multi-resource multi-area power system with redox flow battery units", Control Engineering Practice, Vol. 89, pp. 204-227, 2019.

[7]. V.P. Singh, N. Kishor, and P. Samuel, "Improved load frequency control of power system using LMI based PID approach", Journal of the Franklin Institute, Vol. 354, No. 15, pp. 6805-6830, 2017.

[8]. F.L. Lewis, Optimal control, New York: Wiley, 1986.

[9]. A. E. Jr. Bryson, Y. Ho, Applied optimal control, New York: Hemisphere,1975.

[10]. M. A. Mahmud, "an alternative LQR-based excitation controller design for power systems to enhance small-signal stability", International Journal of Electrical Power and Energy Systems, Vol. 63, pp. 1-7, 2014.

[11]. Z. Han, X. Nan, H. Chen, Y. Huang, and B. Zhao, "Energy-efficient control of electric vehicles based on linear quadratic regulator and phase plane analysis", Applied Energy, Vol. 213, pp. $639-657,2018$.

[12]. M. Abdillah, H. Setiadi, A. B. Reihara, K. Mahmoud, I. W. Farid, and A. Soeprijanto, "Optimal selection of LQR parameter using AIS for LFC in multi-area power system", Journal of Mechatronics, Electrical Power, and Vehicular Technology, Vol. 7, No. 2, pp. 93 - 104, 2016.

[13]. F. Z. Tria, K. Srairi, M. T. Benchouia, B. Mahdad, and M. E. Benzouid, “An hybrid control based on fuzzy logic and a second order sliding mode for MPPT in wind energy conversion systems", International Journal on Electrical Engineering and Informatics, Vol. 8, No. 4, pp. 711-726, 2016.

[14]. Z. Husain, "Fuzzy logic expert system for incipient fault diagnosis of power transformers", International Journal on Electrical Engineering and Informatics, Vol. 10, No. 2, pp. 200$317,2018$.

[15]. K. R. M. V. Chandrakala and S. Balamurugan, "Adaptive neuro-fuzzy scheduled load frequency controller for multi-source multi-area system interconnected via parallel AC-DC Links", International Journal on Electrical Engineering and Informatics, Vol. 10, No. 2, pp. 479-490, 2018.

[16]. A. Giannakis, A. Karlis, and L. Y. Karnavas, "A combined control strategy of a DFIG based on a sensorless power control through modified phase-locked loop and fuzzy logic controllers", Renewable Energy, Vol. 121, pp. 489-501, 2018.

[17]. A. Youssef, M. El Telbany, A. Zekry, "Reconfigurable generic FPGA implementation of fuzzy logic controller for MPPT of PV systems", Renewable and Sustainable Energy Reviews, Vol. 82, pp. 1313-1319, 2018.

[18]. E. Hart, P. Ross, and J. Nelson, "Producing robust schedules via an artificial immune system", Proceedings of the International Conference on Electronic Commerce 1998 (ICEC'98), April 6-9, Seoul, Korea, 1998.

[19]. E. Hart, and P. Ross, "An immune system approach to scheduling in changing environments", Proceedings of The Genetic and Evolutionary Computation Conference 1999 (GECCO’99), July 13-17, Florida, USA, 1999. 
[20]. N. Bayar, S. Darmoul, S. Hajri-Gabouj, and H. Pierreval, "Fault detection, diagnosis and recovery using Artificial Immune Systems: A review", Engineering Applications of Artificial Intelligence, Vol. 46, pp. 43-57, 2015.

[21]. P. Saurabh, P., and B. Verma, "An efficient proactive artificial immune system based anomaly detection and prevention system", Expert Systems with Applications, Vol. 60, pp. 311-320, 2016.

[22]. A. B. D. Fernandes, M. M. Freire, P. P. A. Fazendeiro, and P. R. M. Inacio, "Applications of artificial immune systems to computer security: A survey", Journal of Information Security and Applications, Vol. 35, pp. 138-159, 2017.

[23]. C. H. Silva-Santos, R. P. Goulart, F. Bertelli, and N. Cheung, "An artificial immune system algorithm applied to the solution of an inverse problem in unsteady inward solidification", Advances in Engineering Software, Vol. 121, pp. 178-187, 2018.

[24]. B. K. Sahu, T.K. Pati, J. R. Nayak, S. Panda, and S. K. Kar, "A novel hybrid LUS-TLBO optimized fuzzy-PID controller for load frequency control of multi-source power system", International Journal of Electrical Power \& Energy Systems, Vol. 74, pp.58-69, 2016.

[25]. M. Gheisamejad, "An effective hybrid harmony search and cuckoo optimization algorithm based fuzzy PID controller for load frequency control”, Applied Soft Computing, Vol. 65, pp. 121-138, 2018.

[26]. G. C. Silva, E. E.O. Carvalho, and W. M. Caminhas, "An artificial immune systems approach to Case-based Reasoning applied to fault detection and diagnosis", Expert Systems with Applications, Vol. 140, pp. 1-15, 2020.

[27]. D. Li, S. Liu, F. Gao, and X. Sun, "Continual learning classification method with new labeled data based on the artificial immune system", Applied Soft Computing Journal, Vol. 94, pp. 1-12, 2020.

[28]. S. Aldhaheri, D. Alghazzawi, L. Cheng, A. Barnawi, and B. A. Alzahrani, "Artificial Immune Systems approaches to secure the internet of things: A systematic review of the literature and recommendations for future research", Journal of Network and Computer Applications, Vol. 157, pp. 1-24, 2020.

[29]. H. Saadat, Power system analysis, 2nd Edition, Mc GrawHill, 2004.

[30]. I. Robandi, "An improvement of frequency performance in a power system optimization via controller parameters design using genetic algorithm", this paper is prepared for the 6th IEEE Asia-Pasific conference on Circuits and System (IEEE-APCCAS'02), 28-31 October 2002, Bali, INDONESIA.

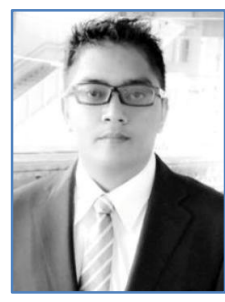

Muhammad Abdillah was born in Pasuruan. He received Sarjana Teknik (equivalent to B.Eng.), and Magister Teknik (equivalent to M.Eng.) degrees from Department of Electrical Engineering, Institut Teknologi Sepuluh Nopember (ITS), Surabaya, Indonesia in 2009 and 2013, respectively. He obtained Dr. Eng. from Graduate School of Engineering, Hiroshima University, Japan in 2017. He is currently appointed as an assistant professor at Department of Electrical Engineering, Universitas Pertamina, Jakarta, Indonesia. His research interests are power system operation and control, power system optimization, robust power system security, power system stability, intelligent control and system, and artificial intelligences (optimization, machine learning, deep learning). 